\title{
Work from Home (WFH) during Covid-19 MRO: Overview and Suitability for Malaysian Tourism Industry Employees
}

\author{
Akmal Adanan ${ }^{1}$, Ameiruel Azwan Ab Aziz ${ }^{2}$, Mohd Hafiz Mohd Hanafiah ${ }^{3}$, Izni Syamsina \\ Saari $^{4}$, Noor Ibtisam Abdul Karim ${ }^{5}$ \\ \{akmaladanan@uitm.edu.my ${ }^{1}$, ameirul@uitm.edu.my ${ }^{2}$, hafizhanafiah@uitm.edu.my ${ }^{3}$, \\ izni_syamsina@uitm.edu.my ${ }^{4}$,noor_ibtisam@uitm.edu.my ${ }^{5}$ \} \\ Universiti Teknologi MARA, Malaysia ${ }^{1,2,3,4,5}$
}

\begin{abstract}
Due to Movement Restriction Order (MRO), public and private organisations have optimised the Work from Home (WFH) policy to most of their staff, including employees in the tourism industry. This paper investigates the situation faced by the tourism employees working from home, identifying the challenges and opportunities during the enforcement. The empirical results from 217 respondents identified the situation and suitability of WFH during MRO among tourism employees in Malaysia. The respondents disagree that the job responsibilities are suitable to be conducted from home, especially when it requires the system that could not be assessed from home and in-person interactions. WFH affects employees' work effort when finding a balance between work, home life (health, friends, family, leisure, children, and home maintenance) and at the same time to stay productive. Even WFH give a high autonomy in scheduling tasks, not all tourism work is suitable to be conducted from home. Moreover, WFH has given room for improvements in knowledge development and organisation. Practically, this study provides insights for the management in organisations by highlighting the factors causing the challenges to the staff, promoting satisfaction, productivity, and opportunity for a better quality of working from home in the future.
\end{abstract}

Keywords: Covid-19, Tourism Management, Work from Home

\section{Introduction}

There are about 3.5 million employees in Malaysia working in the tourism industry. Over the years, this field has significant advances in the rate of employment due to progressive tourism activities in the country. The Department of Statistics Malaysia [1] reported the total employment in the tourism industry grew by $4.9 \%$, equivalent to 3.5 million employees in 2018 that contributed $23.5 \%$ compared to $22.9 \%$. In that notion, food and beverage serving services and retail trade recorded the highest employment in the tourism industry with a share of $34.1 \%$ and $33.1 \%$, respectively.

Nevertheless, the recent outbreak of Covid-19 pandemic has dramatically changed the landscape of tourism industry in Malaysia. The unexpected and overpowering pandemic triggers multi-sectoral business operations and the closures of many non-essential businesses, including the tourism industry. The negative effect of the pandemic is evident in the dramatic statistical data of tourism activities in the first quarter of the year 2020. Malaysia recorded 4,233,425 
tourist arrivals for the first quarter of 2020, a decrease of $36.8 \%$ compared to the same period in 2019, and a decline of $41.5 \%$ tourist expenditure for the first quarter a total of RM12.5 billion, compared to RM21.4 billion registered for the same period last year. Furthermore, the per capita expenditure showed 7.4\% declined, from RM3,201.8 in 2019 to RM2,964.5, and a drop off 1.9 nights, which was 6.0 nights in 2019 to 4.1 nights on the average length of stay (ALOS) in Malaysia [2].

The global pandemic forces the concerns for widespread practise of social distancing to ensure limited physical contact of tourism employees and customers in the endeavour to curb the spread of Covid-19. Due to the very reason, many tourism organisations, both public and private, have answered to the call for Work from Home (WFH) policy to ensure the Movement Restriction Order (MRO) enforced by the government could be objectively achieved. It is expected that by increasing the number of employees who apply WFH as a new working norm would be more likely help to reduce the number of infections at an economical cost that is lower than other containment policies.

WFH has always been a topic of interest in various fields for the past decades. However, it does not represent an important topic to study because many believe that it has a significant number of flaws, including employee management, access to work system and productivity. Nevertheless, the Covid-19 pandemic outbreak has provided urgency for studies to look into this new working routine as an alternative to remaining productive in the time of needs.

Previous scholarly work on WFH implementation has documented many advantages of WFH including workplace flexibility, reduction of office overheads, saving energy consumption and a significant increase in worker's productivity. Another identified advantages are the improved recruitment opportunities particularly for female employees, reduction in travel fatigue, travel time, travel cost, parking fees, savings on petrol, promotion of opportunities for dual-income household, effective management of child care arrangements, increased family contact, ability to care for family illnesses, creation of employment opportunities in rural areas, positive environmental impacts by the reduction in petrol consumption, pollution, traffic congestion and accident rates, flexible work arrangement for working mothers and job opportunities for disabled. However, existing literature on WFH is limited to a subset of a specific group of people in a low urgency level for its implementation. With the enforcement of $\mathrm{MRO}$, WFH is no longer an option for tourism employees. Much needs to be learnt from this new working norm as it remains unexplored specifically in the tourism industry.

\section{Problem Statement}

WFH is defined by working day spent in the home environment [3]. Saludin, Karia and Hassan [4] note that there are also different terms used interchangeably with WFH which are 'Teleworking', Telecommuting', 'Homeworking', and 'Working at Home'. Nonetheless, WFH is used in this paper as a term to refer to the definition as mentioned above.

The concept of WFH has been well documented in the existing literature. An overview of the literature that relates to the present study could be seen in the practice of WFH in the United States of America (USA). Nearly 7.6 million employees practise WFH in the USA, representing approximately $4.8 \%$ from the total USA workforce [4]. The industries which had taken a big step in WFH include banking, insurance, financial services, and legal industry. In another example, in the United Kingdom (UK), about 1.27 million telecommuters are representing about $4.6 \%$ of the UK workforce [4]. Meanwhile, it is not a preferable option in Japan because of the 
high cost of home residences in urban areas around cities like Tokyo [4]. The small size of most of Japanese houses and the cost of utility make it inconvenient for the work at home.

Even WFH has been promoted in Malaysia since 1990, still, there is little acknowledgement for WFH implementation [5] and it remains unpopular in Malaysia despite the many benefits that can be obtained from it [6]. The mobile workforce is relatively a new concept for the Malaysian workers [7]. Evidently, there are a few multinational companies had adopted WFH concepts such as Amway International, IBM, American Insurance of Associates (AIA), Grand soft link computers, Motorola, and Texas Instruments. However, the WFH concept still not be widely implemented by business organisations in Malaysia.

The introduction of WFH policy due to Covid-19 outbreak to the employees in performing their jobs is something very new, especially in these challenging times. Since the enforcement of MRO on 18th March 2020, WFH has been the primary option for employees to minimise physical contacts. WFH demands employees to remain productive, and at the same time attention have to be given to take care of the household and family every day during the quarantine. It forces the use of an extensive amount of physical energy and emotions where they are accustomed to working in the office every day, but now shifted to WFH. Even though many empirical pieces of evidence have pointed out the positive impact of WFH in curbing the spread of the Covid-19, however, Malaysia still has limited in-depth studies on WFH [5][7][8]. Instantaneous implementation, lack of preparation and readiness might result in different reactions from the employees. There are many factors to be considered in order to be productive in performing work-related tasks, especially the location and surroundings. Some employees might be able to shift to WFH relatively quickly and for some employees, however, performing regular work from home is challenging.

Therefore, this paper intends to present an overview of WFH situation faced by employees, specifically in the tourism industry and investigate their perceptions on the suitability of WFH in the months after the pandemic outbreak. Specifically, the objectives of this study are:

1. To identify the overview of WFH among tourism employees in Malaysia during MRO.

2. To identify the suitability of WFH among tourism employees in Malaysia.

\section{Research Methodology}

The current study is a descriptive quantitative and employed convenience sampling techniques. Data were collected from 217 respondents from both public and private organisations in the tourism industry practising WFH during the enforcement period. The sectors that the respondents attached include tourism destination, accommodation, tourism product, transportation, food and beverages, tourism services, business tourism, and spa. The responses were collected through online questionnaires distributed via Google form platform. For triangulation purpose, qualitative data were collected through open-ended questions on the same platform and was analysed thematically. The data collection was conducted in April 2020 during the MRO implementation when all the employees are compelled for WFH.

Secondary data were also collected from relevant academic articles and journals. In the review, more than 20 articles and journals were identified, and 11 of them were critically reviewed to address the formulated questions. Finally, by charting the data, assembling, summarising and reporting the results based on the authors' experience, existing theories and models, incorporating statistical data, reports and proceedings published by Ministry of Tourism, Art and Culture Malaysia (2020). 


\section{Results and Discussion}

\subsection{Profile}

\begin{tabular}{|c|l|c|c|c|c|}
\hline \multicolumn{5}{|c|}{ Gender } \\
\hline \multicolumn{2}{|c|}{} & Frequency & \% & Valid \% & Cumulative \% \\
\hline Valid & Female & 129 & 59.4 & 59.4 & 59.4 \\
\hline & Male & 88 & 40.6 & 40.6 & 100.0 \\
\hline & Total & 217 & 100.0 & 100.0 & \\
\hline
\end{tabular}

The study was participated by $40.6 \% \quad(n=88)$ males and $59.4 \%(n=129)$ females' respondents. The majority of the respondents are from the two different groups of age which are $38.7 \%(\mathrm{n}=84)$ of the respondents belonging to the age group of 18 to 30 years, and $33.2 \%$ $(n=72) 31$ to 40 years respectively. $18.4 \%(n=40)$ of the respondents are in the age group of 41 to 50 years; $8.3 \%(n=18)$ are 51 to 61 years of age, and $1.4 \%(n=3)$ respondents are 61 years of age and above.

\begin{tabular}{|c|l|c|c|c|c|}
\hline \multicolumn{6}{|c|}{ Gender } \\
\hline \multicolumn{2}{|l|}{} & Frequency & \% & Valid \% & Cumulative \% \\
\hline Valid & Single & 85 & 39.2 & 39.2 & 39.2 \\
\hline & Married without children & 18 & 8.3 & 8.3 & 47.5 \\
\hline & Married with children & 108 & 49.8 & 49.8 & 97.2 \\
\hline & Single parents & 6 & 2.8 & 2.8 & 100.0 \\
\hline & Total & 217 & 100.0 & 100.0 & \\
\hline
\end{tabular}

In the marital status context, $49.8 \%(\mathrm{n}=108)$ of the respondents are in the group of married with children who represent the majority of the population, followed by single $39.2 \%(n=85)$, married without children $8.3 \%(\mathrm{n}=18)$ and single parent $2.8 \%(\mathrm{n}=6)$. The majority of respondents, $76.5 \%(n=166)$, live in the urban area, and $23.5 \%(n=51)$ of them live in the rural residential area. 149 respondents are work in private organisations and 68 work in the public sector.

\subsection{The Suitability of Job Responsibility to be Performed at Home}

The study reveals that $43.8 \%(n=95)$ respondents agree that their job responsibilities are suitable to be conducted from home meanwhile, $56.2 \%(n=122)$ respondents disagreed with it based on several reasons as below:

"Tourism is a personalised industry, always feels better when one has a face-to-face discussion."

"Impossible to handle important issues on the spot, especially human relationships, matter in between employees."

"Nobody is travelling, so no income, no salary / No incoming sales for travel demand and no job to do." 


\subsection{Efficient Working Hours}

In general, $53 \%(\mathrm{n}=115)$ respondents stated that the time between $10 \mathrm{am}-2 \mathrm{pm}$ considered as their efficient working hours of doing their tasks. Meanwhile, $19.45 \%(n=52)$ of respondents prefer to work between 2 pm- 6 pm daily. Interestingly only $4.1 \%(n=9)$ respondents preferred to work 6 am-10 am, and $4.6 \%(n=10)$ to work at $6 \mathrm{pm}-0 \mathrm{pm}$ respectively.

Some of the respondents stated that the time between $10 \mathrm{am}-2 \mathrm{pm}$ is the perfect time to do their office tasks because:

"After doing mornings chore and break."

"Good time to connect with colleagues, clients, etc."

"The most active and productive time to work."

\subsection{Remain Productive at Home}

\begin{tabular}{|c|c|c|c|c|c|}
\hline \multicolumn{7}{|c|}{ Descriptive Statistics } \\
\hline & $\mathbf{N}$ & Minimum & Maximum & Mean & Std. Deviation \\
\hline Illustration & 217 & 1.33 & 5.00 & 3.2780 & .70347 \\
\hline Valid N (listwise) & 217 & & & & \\
\hline
\end{tabular}

A descriptive statistic illustrates how the respondents remain productive work from home (WFH). Respondents revealed that they could be productive by working from home $(\mathrm{M}=3.09$, $\mathrm{SD}=1.155)$. However, the majority of respondents expressed that work from home challenges their ability to perform routine tasks $(\mathrm{M}=3.53, \mathrm{SD}=1.110)$. As evident, some of the respondents stated that the demand to complete tasks during WFH stressed them out $(\mathrm{M}=3.21, \mathrm{SD}=1.193)$.

Other initiatives that are stated by the respondents to remain productive are:

"Set a specific office time at home."

"Clear time management in doing work, house chores and taking care of kids."

"Reorganise and keep in touch with colleagues regarding works."

Several respondents also stated that they did yoga, running, cooking, planting, and reading to stay productive at home.

\subsection{Challenges Working at Home}

\begin{tabular}{|c|c|c|c|c|c|}
\hline \multicolumn{7}{|c|}{ Descriptive Statistics } \\
\hline & N & Minimum & Maximum & Mean & Std. Deviation \\
\hline Challenges & 217 & 1.00 & 5.00 & 3.6945 & .80160 \\
\hline Valid N (listwise) & 217 & & & & \\
\hline
\end{tabular}

The respondents agreed that they had to do extra household chores while working from home ( $\mathrm{M}=3.71, \mathrm{SD}=1.263)$. Additionally, the respondents responded that they had to entertain the children $(M=3.25, S D=1.416)$ and had to manage the household needs $(M=3.69, S D=1.171)$ while performing their tasks at home. Furthermore, the majority of the respondents also agreed that it is challenging to manage working time when working from home $(M=3.64, S D=1.147)$. On the technical aspects, most of the respondents stated that they have insufficient reference documents at home $(\mathrm{M}=4.10, \mathrm{SD}=1.161)$ and limited office equipment (computer/laptop) $(\mathrm{M}=3.91, \mathrm{SD}=1.311)$ available to accomplish tasks. Notably, the respondents also struggled 
with poor internet access $(\mathrm{M}=3.87, \mathrm{SD}=1.328)$ to perform tasks online. The unavailability of application $(\mathrm{m}=3.93, \mathrm{SD}=1.240$, item 8$)$ also became of the challenges faced by the respondents. The majority of respondents disagreed that they have a lack of skills in using online software $(\mathrm{M}=2.98, \mathrm{SD}=1.359$, item 9) but agreed that they face a challenge to deal with the nonoperational tourism-related services $(\mathrm{M}=3.87, \mathrm{SD}=1.155$, item 10) during $\mathrm{MRO}$.

\section{Conclusion}

This study addresses a need in the current literature to understand the experience of employees working from home for the first time during Covid-19 pandemic. It includes the opinion of tourism employees towards work from the home policy during the implementation of MCO. An important finding of this research is that not all kinds of jobs or industries are suitable to be conducted from home. It needs a particular approach, especially when it relates to the situation, readiness, system, and technologies use in performing the jobs.

In reality, it is a puzzle when home becomes a place of work. The distractions from personal life often stand in our way to fulfil work responsibilities. Understanding the challenges and the needs of employees provides employers with an opportunity to understand better and help their employees set up a supportive and controlled work environment.

\section{Limitation and Future Research}

This study is not free from limitations where it is limited to study the perceptions of employees in tourism industry pertaining to the implementation of WFH in the early period of MRO enforcement based on statistical data gathered from a specific group of respondents. The study does not measure the relationship of independent variables to dependent variables to ascertain the satisfaction level of WFH. In addition to that, this study did not compare the perceptions between different genders. Therefore, it is suggested that in the future, research can be carried out to investigate empirically with a larger group of respondents as well as the differences in satisfaction level of WFH based on gender. The results of the present study provide several potential avenues for future research. Due to Covid-19, employees of all the sectors are introduced to the concept of WFH for the first time. Hence a comparative study of the perceptions of employees in different sectors can be conducted.

\section{References}

[1] Department of Statistics Malaysia, "Tourism Satellite Account 2018," Department of Statistics Malaysia Official Portal, 2020. [Online]. Available: https://www.dosm.gov.my/v1/.

[2] Tourism Malaysia Corporate Site, "Malaysia welcomed 4.23 million international tourists for Q1 2020, down $36.8 \%$ from last year." [Online]. Available: https://www.tourism.gov.my/media/view/malaysia-welcomed-4-23-million-internationaltourists-for-q1-2020-down-36-8-from-last-yea.

[3] J. Sayers and N. Monin, The global garage: Home-based business in New Zealand. Cengage Learning Australia, 2005.

[4] N. A. Saludin, N. Karia, and H. Hassan, "Working from Home (WFH): Is Malaysia ready for digital society," in Entrepreneurship Vision 2020: Innovation, Development Sustainability, and Economic Growth-Proceedings of the 20th International Business Information Management 
Association Conference, IBIMA 2013, 2020, pp. 981-989.

[5] M. Asaari and N. Karia, "Factors Toward Telecommuting: An Exploratory Study," Malaysian Manag. Rev., vol. 36, no. 1, 2001.

[6] N. O. Ndubisi and C. Kahraman, “Teleworking adoption decision-making processes,” J. Enterp. Inf. Manag., 2005.

[7] A. A. K. Hamsa, L. C. Oniyirimba, and S. Ahmad, "An exploratory analysis of factors toward the emergence of teleworking in Malaysia," in Proceedings of the Thirtieth Hawaii International Conference on System Sciences, 1997, vol. 4, pp. 99-109.

[8] M. P. Pérez, A. M. Sánchez, M. P. de Luis Carnicer, and M. J. V. Jiménez, "The environmental impacts of teleworking," Manag. Environ. Qual. An Int. J., 2004. 